\title{
Gambaran Rencana Pulang Warga Binaan pada Sebuah Lembaga Pemasyarakatan Perempuan di Indonesia: Studi Pendahuluan
}

\author{
Sayyidati Ummy Nurul Baity ${ }^{1}$, Megah Andriany ${ }^{1, *}$ \\ ${ }^{1}$ Departemen Ilmu Keperawatan Fakultas Kedokteran, Universitas Diponegoro, Semarang, Indonesia \\ megahandriany@fk.undip.ac.id
}

\begin{abstract}
Introduction: As the development of the time, women committed criminal activities usually dominated by man. That crimes resulted negative stigma by society. So, it requires effective many discharge planning for female inmates to face the freedom. This study is useful for correctional nurses because of nurse basic role for provides female inmates discharge planning.

Methods: The study about description female inmate's discharge planning has already been studied in qualitative method, but it has not yet been studied in quantitative. The research purpose is to know the discharge planning of the return of the inmates in a female prison in Indonesia. This study was descriptive quantitative research method using with cross sectional approach. This research used questionnaire as the instrument. There were 25 samples that chosen by total sampling technique on a women's prison in Indonesia. The analysis data using univariate analysis.

Results: $92 \%$ of respondents would plan follow up skills from prisons, $68 \%$ of respondents would do legal plan, $100 \%$ of respondents would do the plan to maintain physical condition, $70.3 \%$ of respondents would do social interaction plan, $98 \%$ of respondents would do the mental spiritual plan, $65 \%$ of respondents would do the plan to meet the needs of residence and economy.

Conclusion: There were various planning of female inmates before release from a prison. Correctional nurses are recommended to give more attention to the psychosocial problems of the women inmates and able to develop discharge planning program for the woman inmates by their freedom so that the inmates are ready to return to the society.
\end{abstract}

Keywords: Correctional nurses, Discharge planning, Female inmate

\begin{abstract}
Abstrak
Pendahuluan: Perkembangan zaman membuat wanita melakukan tindak kriminal yang biasa dilakukan oleh laki-laki yang mengakibatkan stigma negatif dari masyarakat. Meskipun mendapatkan stigma negatif, warga binaan mempunyai berbagai rencana pulang menjelang kebebasan. Penelitian tentang gambaran rencana pulang warga binaan wanita diperlukan perawat correctional dalam menjalankan perannya sebagai perencana pulang. Penelitian gambaran rencana pulang warga binaan wanita, telah diteliti secara kualitatif dan belum secara kuantitatif. Tujuan penelitian ini untuk mengetahui gambaran rencana pulang warga binaan pada sebuah Lapas wanita di Indonesia.

Metode: Penelitian ini menggunakan metode penelitian kuantitatif dengan rancangan deskriptif dan pendekatan cross-sectional. Instrumen penelitian ini menggunakan kuesioner, teknik sampling yang digunakan adalah total sampling pada sebuah Lapas wanita di Indonesia dengan jumlah sampel 25 responden.

Hasil: Sebanyak 92\% responden akan melakukan rencana menindaklanjuti keterampilan dari Lapas, $68 \%$ responden akan melakukan rencana hukum, $100 \%$ responden akan melakukan rencana
\end{abstract}


mempertahankan kondisi fisik, 70,3\% responden akan melakukan rencana interaksi sosial, 98\% responden akan melakukan rencana mental spiritual, 65\% responden akan melakukan rencana pemenuhan kebutuhan tempat tinggal dan ekonomi.

Kesimpulan: Terdapat beberapa rencana warga binaan perempuan menjelang kebebasan. Perawat Lapas disarankan lebih memperhatikan masalah psikososial warga binaan wanita serta mampu mengembangkan program perencanaan pulang yang sesuai bagi warga binaan wanita sehingga warga binaan siap untuk kembali di lingkungan masyarakat.

Kata kunci: Perawat lapas, Perencanaan pulang, Warga binaan pemasyarakatan wanita

\section{PENDAHULUAN}

Kejadian pemenjaraan wanita semakin bertambah dengan cepat (Parker \& Reckdenwald, 2008). Menyandang status sebagai mantan warga binaan merupakan beban yang amat berat dikarenakan stigma dari masyarakat (Puspitasari, 2015). Warga binaan wanita telah diberi stigma yang lebih buruk dibandingkan dengan warga binaan pria. Masyarakat enggan menerima mantan warga binaan untuk bekerjasama, masyarakat sulit untuk memberikan kepercayaan kepada mantan warga binaan, bahkan masyarakat bersikap waspada terhadap mantan warga binaan (Al-Jauhar \& Imron, 2014).

Menghadapi berbagai dampak sosial, warga binaan masih mempunyai masa depan setelah bebas. Warga binaan masih memiliki harapan untuk dapat kembali ke dalam masyarakat (Shofia, 2009). Berdasar harapan tersebut, warga binaan mempunyai berbagai rencana pulang. Setelah bebas, warga binaan umumnya mencari pekerjaan, mendapatkan identifikasi hukum, mencari tempat tinggal, menetapkan perawatan medis dan/atau kejiwaan yang diperlukan (Fontana \& Beckerman, 2007).

Studi pendahuluan yang dilakukan pada sebuah lembaga pemasyarakatan (Lapas) wanita di Indonesia didapatkan suatu fenomena bahwa discharge planning dilakukan mulai dari awal masuk ke dalam Lapas melalui program kepribadian dan program kemandirian. Peran perawat correctional pada sebuah Lapas tersebut adalah pemberian pelayanan umum (pemeriksaan dan perawatan orang sakit, penyuluhan kesehatan, membuat rujukan ke rumah sakit) dan pelayanan khusus (pelayanan kepada warga binaan wanita yang memerlukan penanganan secara spesifik dan profesional seperti TB, HIV/AIDS). Layanan kesehatan mental warga binaan kurang begitu diperhatikan oleh perawat correctional. Pemberian pelayanan kesehatan pada Lapas hanya dilakukan untuk warga binaan yang sakit secara fisik.

Rencana tersebut dapat menjadi dasar bagi perawat correctional dalam menjalankan perannya sebagai discharge planner. Penelitian gambaran rencana pulang warga binaan wanita, telah diteliti secara kualitatif dan belum secara kuantitatif. Data mengenai gambaran rencana pulang warga binaan masih sangat terbatas khususnya warga binaan wanita di Indonesia, oleh karena itu penelitian ini dibutuhkan untuk mengetahui gambaran rencana pulang warga binaan wanita.

Rencana tersebut dapat menjadi dasar bagi perawat correctional dalam menjalankan perannya sebagai discharge planner. Penelitian gambaran rencana pulang warga binaan wanita, telah diteliti secara kualitatif dan belum secara kuantitatif. Data mengenai gambaran rencana pulang warga binaan masih sangat terbatas khususnya warga binaan wanita di Indonesia, oleh karena itu penelitian ini 
dibutuhkan untuk mengetahui gambaran rencana pulang warga binaan wanita.

\section{METODE}

Penelitian ini menggunakan metode penelitian kuantitatif dengan rancangan deskriptif survei dan pendekatan cross sectional. Populasi dalam penelitian ini adalah warga binaan wanita dengan sisa masa pidana satu sampai tiga bulan terakhir. Pengambilan sampel dalam penelitian ini menggunakan teknik total sampling pada sebuah Lapas wanita di Indonesia dengan sampel sebanyak 25 responden. Data diambil menggunakan instrumen kuesioner, selanjutnya kuesioner telah dilakukan uji expert dan uji validitas yang memiliki hasil valid pada 33 pernyataan dan telah dilakukan uji reliabilitas yang memiliki koefisien alfa sebesar 0,756. Namun, tiga pernyataan dalam kuesioner memiliki arti yang sama dengan pernyataan sebelumnya. Oleh karena itu, penelitian ini hanya menggunakan 30 pernyataan dalam kuesioner. Pengambilan data dilakukan pada bulan Juli 2017. Analisis data dalam penelitian ini menggunakan analisis univariat. Penelitian ini telah disetujui oleh Komisi Etik Penelitian Kesehatan FK Universitas Negeri Sebelas Maret Surakarta dan RSUD Dr. Moewardi Surakarta.

\section{HASIL}

Tabel 1. Distribusi Frekuensi Karakteristik Responden $(N=25)$

\begin{tabular}{cccc}
\hline No & \multicolumn{1}{c}{ Variabel } & f & \% \\
\hline 1. & Usia & 20 & 80 \\
& $-\quad 18-40$ tahun & 5 & 20 \\
\hline 2. & $-\quad$ Pendidikan terakhir & & \\
& $-\quad$ Pendidikan rendah & 4 & 16 \\
& $-\quad$ Pendidikan menengah & 15 & 60 \\
& $-\quad$ Pendidikan tinggi & 6 & 24 \\
& & &
\end{tabular}

\begin{tabular}{clcc}
\hline No & \multicolumn{1}{c}{ Variabel } & f & \% \\
\hline 3. & Sisa masa pidana & & \\
& $-\quad 0-1$ bulan & 11 & 44 \\
& $-\quad$ 2 bulan & 11 & 44 \\
& - 3 bulan & 3 & 12 \\
\hline $4 . \quad$ Status Menikah & & \\
& - Belum menikah & 5 & 20 \\
& - Menikah & 12 & 48 \\
$\quad$ - Janda & 8 & 32 \\
\hline 5 $\quad$ Frekuensi kunjungan & & \\
& keluarga & & \\
& - Rutin & 9 & 36 \\
& - Tidak Rutin & 7 & 28 \\
& $-\quad$ Tidak Pernah & 9 & 36 \\
\hline
\end{tabular}

Tabel 2. Rencana Menindaklanjuti Ketrampilan yang Diperoleh di Lapas $(N=25)$

\begin{tabular}{|c|c|c|c|c|c|c|c|}
\hline \multirow{2}{*}{ No } & \multirow{2}{*}{ Variabel } & \multicolumn{2}{|c|}{ Ya } & \multicolumn{2}{|c|}{ Tidak } & \multicolumn{2}{|c|}{ Total } \\
\hline & & $\mathrm{f}$ & $\%$ & $\mathrm{f}$ & $\%$ & $\mathrm{f}$ & $\%$ \\
\hline 1. & $\begin{array}{l}\text { Menerapkan } \\
\text { keterampilan } \\
\text { yang diperoleh } \\
\text { dari Lapas untuk } \\
\text { menambah } \\
\text { penghasilan }\end{array}$ & 22 & 88 & 3 & 12 & 25 & 100 \\
\hline 2. & \begin{tabular}{lr}
\multicolumn{2}{l}{ Mengajarkan } \\
keterampilan \\
yang diperoleh \\
dari & Lapas \\
kepada & orang \\
lain. & \\
\end{tabular} & 23 & 92 & 2 & 8 & 25 & 100 \\
\hline 3. & $\begin{array}{l}\text { Mempelajari } \\
\text { lebih dalam lagi } \\
\text { keterampilan } \\
\text { yang diperoleh } \\
\text { dari Lapas agar } \\
\text { lebih bermanfaat. }\end{array}$ & 24 & 96 & 1 & 4 & 25 & 100 \\
\hline
\end{tabular}

Tabel 3. Rencana Hukum $(N=25)$

\begin{tabular}{llllllll}
\hline & & \multicolumn{3}{c}{ Ya } & \multicolumn{2}{c}{ Tidak } & \multicolumn{2}{c}{ Total } \\
\cline { 3 - 8 } No & Variabel & $\mathrm{f}$ & $\%$ & $\mathrm{f}$ & $\%$ & $\mathrm{f}$ & $\%$ \\
\hline 1. & $\begin{array}{l}\text { Lapor ke Balai } \\
\text { Pemasyarakatan } \\
\text { (Bapas) }\end{array}$ & 19 & 76 & 6 & 24 & 25 & 100 \\
\hline 2. & $\begin{array}{l}\text { Menyelesaikan } \\
\text { permasalahan } \\
\text { dengan korban }\end{array}$ & 4 & 16 & 21 & 84 & 25 & 100 \\
\hline 3. & $\begin{array}{l}\text { Melaporkan } \\
\text { balik ke Polisi } \\
\text { orang yang } \\
\text { melaporkan saya }\end{array}$ & 5 & 20 & 20 & 80 & 25 & 100 \\
\hline
\end{tabular}


Tabel 3. Rencana Hukum (N=25) (Lanjutan)

\begin{tabular}{|c|c|c|c|c|c|c|c|}
\hline \multirow{2}{*}{ No } & \multirow{2}{*}{ Variabel } & \multicolumn{2}{|c|}{ Ya } & \multicolumn{2}{|c|}{ Tidak } & \multicolumn{2}{|c|}{ Total } \\
\hline & & f & $\%$ & $\mathrm{f}$ & $\%$ & f & $\%$ \\
\hline 4. & $\begin{array}{l}\text { Menaati } \\
\text { peraturan hukum } \\
\text { yang berlaku di } \\
\text { Indonesia }\end{array}$ & 24 & 96 & 1 & 4 & 25 & 100 \\
\hline 5. & $\begin{array}{lr}\text { Hati-hati } & \text { dalam } \\
\text { bertindak } & \text { agar } \\
\text { tidak } & \text { masuk } \\
\text { kembali } & \text { ke } \\
\text { dalam Lapas } & \end{array}$ & 25 & 100 & 0 & 0 & 25 & 100 \\
\hline 6. & $\begin{array}{l}\text { Menjalankan } \\
\text { norma-norma } \\
\text { yang berlaku di } \\
\text { masyarakat }\end{array}$ & 25 & 100 & 0 & 0 & 25 & 100 \\
\hline
\end{tabular}

Tabel 4. Rencana Mempertahankan Kondisi Fisik $(N=25)$

\begin{tabular}{llllllll}
\hline \multirow{2}{*}{ No } & Variabel & \multicolumn{3}{c}{ Ya } & \multicolumn{2}{c}{ Tidak } & \multicolumn{2}{c}{ Total } \\
\cline { 2 - 7 } & $\mathrm{f}$ & $\%$ & $\mathrm{f}$ & $\%$ & $\mathrm{f}$ & $\%$ \\
\hline 1. & $\begin{array}{l}\text { Menjaga } \\
\text { kesehatan }\end{array}$ & 25 & 100 & 0 & 0 & 25 & 100 \\
\hline 2. & $\begin{array}{l}\text { Mencari } \\
\text { pelayanan } \\
\text { kesehatan untuk } \\
\text { pengobatan } \\
\text { apabila sakit }\end{array}$ & 25 & 100 & 0 & 0 & 25 & 100 \\
\hline 3. & $\begin{array}{l}\text { Berolahraga agar } \\
\text { tetap sehat }\end{array}$ & 25 & 100 & 0 & 0 & 25 & 100 \\
\hline 4. & $\begin{array}{l}\text { Memenuhi } \\
\text { kebutuhan } \\
\text { makan } \\
\text { minum dan }\end{array}$ & 25 & 100 & 0 & 0 & 25 & 100 \\
\hline 5. & $\begin{array}{l}\text { Memenuhi } \\
\text { kebutuhan } \\
\text { istirahat }\end{array}$ & 25 & 100 & 0 & 0 & 25 & 100 \\
\hline
\end{tabular}

Tabel 5. Rencana Interaksi Sosial $(N=25)$

\begin{tabular}{clcccccc}
\hline \multirow{2}{*}{ No } & Variabel & \multicolumn{3}{c}{ Ya } & \multicolumn{2}{c}{ Tidak } & \multicolumn{2}{c}{ Total } \\
\cline { 3 - 7 } & $\mathrm{f}$ & $\%$ & $\mathrm{f}$ & $\%$ & $\mathrm{f}$ & $\%$ \\
\hline 1. & $\begin{array}{l}\text { Menyambung } \\
\text { silaturahmi } \\
\text { dengan keluarga }\end{array}$ & 25 & 100 & 0 & 0 & 25 & 100 \\
\hline 2. & $\begin{array}{l}\text { Menyambung } \\
\text { silaturahmi } \\
\text { dengan tetangga }\end{array}$ & 23 & 92 & 2 & 8 & 25 & 100 \\
\hline 3. & $\begin{array}{l}\text { Berkumpul } \\
\text { dengan keluarga }\end{array}$ & 25 & 100 & 0 & 0 & 25 & 100 \\
\hline 4. & $\begin{array}{l}\text { Berkumpul } \\
\text { dengan } \\
\text { masyarakat }\end{array}$ & 25 & 100 & 0 & 0 & 25 & 100 \\
\hline 5. & $\begin{array}{l}\text { Membahagiakan } \\
\text { keluarga }\end{array}$ & 25 & 100 & 0 & 0 & 25 & 100 \\
\hline 6. & $\begin{array}{l}\text { Meminta maaf } \\
\text { kepada korban }\end{array}$ & 10 & 40 & 15 & 60 & 25 & 100 \\
\hline & & & & & & & \\
\hline
\end{tabular}

\begin{tabular}{|c|c|c|c|c|c|c|c|}
\hline \multirow{2}{*}{ No } & \multirow{2}{*}{ Variabel } & \multicolumn{2}{|c|}{ Ya } & \multicolumn{2}{|c|}{ Tidak } & \multicolumn{2}{|c|}{ Total } \\
\hline & & $\mathrm{f}$ & $\%$ & $f$ & $\%$ & $\mathrm{f}$ & $\%$ \\
\hline 7. & $\begin{array}{l}\text { Enggan bertemu } \\
\text { dengan orang } \\
\text { yang melaporkan }\end{array}$ & 13 & 52 & 12 & 48 & 25 & 100 \\
\hline 8. & $\begin{array}{lr}\text { Balas dendam } \\
\text { kepada orang } \\
\text { yang melaporkan } \\
\text { saya }\end{array}$ & 4 & 16 & 21 & 84 & 25 & 100 \\
\hline 9. & $\begin{array}{l}\text { Berhubungan } \\
\text { dengan } \\
\text { masyarakat } \\
\text { beberapa hari } \\
\text { setelah bebas }\end{array}$ & 8 & 32 & 17 & 68 & 25 & 100 \\
\hline 10. & $\begin{array}{l}\text { Menghindari } \\
\text { masyarakat } \\
\text { sekitar yang } \\
\text { mengetahui } \\
\text { kejadian }\end{array}$ & 3 & 12 & 22 & 88 & 25 & 100 \\
\hline 11. & $\begin{array}{l}\text { Merawat } \\
\text { keluarga }\end{array}$ & 25 & 100 & 0 & 0 & 25 & 100 \\
\hline 12. & $\begin{array}{l}\text { Mengikuti } \\
\text { kegiatan } \\
\text { masyarakat }\end{array}$ & 25 & 100 & 0 & 0 & 25 & 100 \\
\hline
\end{tabular}

Tabel 6. Rencana Mental Spritual $(N=25)$

\begin{tabular}{|c|c|c|c|c|c|c|c|}
\hline \multirow{2}{*}{ No } & \multirow{2}{*}{ Variabel } & \multicolumn{2}{|c|}{ Ya } & \multicolumn{2}{|c|}{ Tidak } & \multicolumn{2}{|c|}{ Total } \\
\hline & & $\mathrm{f}$ & $\%$ & $\mathrm{f}$ & $\%$ & $\mathrm{f}$ & $\%$ \\
\hline 1. & $\begin{array}{lr}\text { Merenung } & \text { atas } \\
\text { kesalahan } \\
\text { lampau }\end{array}$ & 23 & 92 & 2 & 8 & 25 & \\
\hline 2. & $\begin{array}{lr}\text { Bertaubat } & \text { dari } \\
\text { kesalahan } & \text { yang } \\
\text { diperbuat } & \end{array}$ & 25 & 100 & 0 & 0 & 25 & \\
\hline 3. & $\begin{array}{l}\text { Mengikuti } \\
\text { kegiatan } \\
\text { keagamaan } \\
\text { secara } \\
\text { berkelanjutan }\end{array}$ & 25 & 100 & 0 & 0 & 25 & \\
\hline
\end{tabular}

Tabel 7. Pemenuhan Kebutuhan Tempat Tinggal $(N=25)$

\begin{tabular}{|c|c|c|c|c|c|c|c|}
\hline \multirow[b]{2}{*}{ No } & \multirow{2}{*}{ Variabel } & \multicolumn{2}{|c|}{ Ya } & \multicolumn{2}{|c|}{ Tidak } & \multicolumn{2}{|c|}{ Total } \\
\hline & & $\mathrm{f}$ & $\%$ & $\mathrm{f}$ & $\%$ & $\mathrm{f}$ & $\%$ \\
\hline 1. & $\begin{array}{lr}\text { Kembali } & \mathrm{ke} \\
\text { rumah yang dulu }\end{array}$ & 23 & 92 & 2 & 8 & 25 & 100 \\
\hline 2. & $\begin{array}{l}\text { Mencari tempat } \\
\text { tinggal baru }\end{array}$ & 5 & 20 & 20 & 80 & 25 & 100 \\
\hline 3. & $\begin{array}{l}\text { Melanjutkan } \\
\text { pekerjaan }\end{array}$ & 13 & 52 & 12 & 48 & 25 & 100 \\
\hline 4. & $\begin{array}{l}\text { Mencari } \\
\text { pekerjaan baru } \\
\text { yang halal } \\
\text { apabila tidak } \\
\text { dapat } \\
\text { melanjutkan } \\
\text { pekerjaan lama }\end{array}$ & 24 & 96 & 1 & 4 & 25 & 100 \\
\hline
\end{tabular}

Sayyidati Baity, dkk., Gambaran Rencana Pulang Warga Binaan... 


\section{PEMBAHASAN}

Sebanyak $12 \%$ responden tidak akan menerapkan keterampilan yang diperoleh dari Lapas, kemungkinan karena keterampilan yang diperoleh dari Lapas tidak sesuai dengan peminatan warga binaan atau kurangnya motivasi berwirausaha. Hal ini dikarenakan pelatihan keterampilan yang disediakan serta pendekatan dan strategi yang digunakan dalam proses pembelajaran belum sesuai dengan kebutuhan seluruh warga binaan (Tyaswuri, 2010). Melihat sebagian keterampilan yang diperoleh dari Lapas tidak diterapkan dalam kehidupan setelah bebas, perawat dapat beradvokat untuk mengusulkan dengan memberikan pelatihan untuk mengembangkan kreatifitas dan inovasi program kemandirian yang sesuai dengan sebagian besar minat warga binaan wanita serta beradvokat untuk bekerjasama dengan instruktur pelatihan untuk pembinaan keterampilan secara berkelanjutan kepada bagian bimbingan pemasyarakatan. Seorang instruktur dalam pelatihan ini juga harus menjadi motivator dan partner bagi warga binaan atau peserta pelatihan (Tyaswuri, 2010).

Sebanyak $76 \%$ responden akan lapor ke Bapas (Balai Pemasyarakatan) setelah bebas. Bimbingan Bapas diberikan dengan tujuan agar klien dapat hidup dengan baik didalam masyarakat sebagai warga negara serta bertanggungjawab, untuk memberikan motivasi, agar dapat memperbaiki diri sendiri, dan tidak mengulangi kejahatan (Kellina, 2013). Ada beberapa faktor yang dapat membuat klien kembali melakukan tindak pidana selama menjalani bimbingan dari Bapas, antara lain: faktor ekonomi, faktor sumber daya manusia yang dimiliki klien, dan faktor ketergantungan warga binaan narkoba (Susanto, 2013).

Sebanyak $4 \%$ responden menyatakan tidak akan menaati peraturan hukum di
Indonesia setelah bebas dari Lapas. Kesadaran hukum adalah kesadaran seseorang akan pengetahuan bahwa suatu perilaku tertentu diatur oleh hukum (Suharso \& Retnoningsih, 2005). Peran perawat sebagai collaborator dilakukan karena perawat bekerja sama dengan bagian pelayanan lainnya dengan berupaya mengidentifikasi pelayanan yang diperlukan termasuk diskusi atau tukar pendapat dalam penentuan bentuk pelayanan selanjutnya (Hitchcock, Schubert, \& Thomas, 2003). Dalam hal ini pelayanan lainnya yang dimaksud adalah Balai Pemasyarakatan.

Semua responden menyatakan akan mencari pelayanan kesehatan untuk pengobatan apabila sakit setelah dari Lapas. Kane menyatakan bahwa 74 warga binaan mengakui akan membutuhkan akses layanan kesehatan setelah dibebaskan, termasuk mendapatkan perawatan kesehatan (Mallik-Kane, 2005). Warga binaan wanita yang terkena penyakit TB, HIV atau penyakit menular lainnya memerlukan perawatan yang berkelanjutan setelah bebas dari Lapas. Peran perawat sebagai praktisi kesehatan dibutuhkan dalam mempersiapkan warga binaan wanita yang terkena penyakit TB/ HIV-AIDS sebelum berbaur dengan masyarakat dalam program pre-release.

Semua responden yang akan menyatakan akan memenuhi kebutuhan fisiologis (makan, minum, istirahat serta olahraga) setelah bebas. Perawat membantu klien pada setiap tingkat umur untuk memenuhi kebutuhan fisiologis. Apabila kebutuhan fisiologis ini sudah terpenuhi, maka seseorang akan berusaha untuk memenuhi kebutuhan lain yang lebih tinggi dan begitu seterusnya (Asmadi, 2008). Peran perawat sebagai educator diperlukan dalam peningkatan pengetahuan responden 
agar meningkatnya status kesehatan responden setelah bebas dari Lapas.

Semua responden memiliki rencana untuk silaturahmi dengan keluarga, berkumpul kembali dengan keluarga, membahagiakan keluarga, merawat keluarga, berkumpul dengan masyarakat, mengikuti kegiatan yang ada di masyarakat setelah bebas. Hal tersebut merupakan strategi warga binaan untuk menjalin serta memperkuat kembali hubungan dengan keluarga dan masyarakat setelah bebas. Rencana menyambung silaturahmi oleh beberapa responden didasari atas adanya masalah sosial yang mungkin muncul akibat kurang penerimaan dukungan sosial terhadap warga binaan. Responden merasa kurangnya komunikasi dengan dukungan sosial yang mencerminkan kurangnya penerimaan dukungan sosial terhadap responden sehingga responden merencanakan suatu strategi untuk memperkuat tali kekeluargaan setelah bebas (Andriany, 2008).

Sebanyak $8 \%$ responden tidak akan menyambung silaturahmi dengan tetangga, $13 \%$ responden enggan bertemu dengan orang yang melaporkan, $8 \%$ tidak akan berhubungan dengan masyarakat untuk beberapa hari setelah bebas, 3\% akan menghindar dari masyarakat sekitar yang mengetahui kejadian. Kondisi ini, dalam keperawatan jiwa disebut dengan perilaku isolasi sosial menarik diri. Intervensi keperawatan meliputi; menghubungi konselor sebaya, merujuk pasien ke kelompok pendukung, membantu membangun kembali jaringan keluarga, meningkatkan spiritualitas pasien, membantu pasien menggunakan dukungan berbasis internet, dan mempraktikkan penggunaan terapi diri (Holley, 2007).

$60 \%$ responden menyatakan untuk tidak meminta maaf kepada korban, 84\% responden menyatakan tidak akan menyelesaikan permasalahan dengan korban, dan 16\% responden akan balas dendam. Kondisi ini dapat diakibatkan oleh adanya gangguan proses penerimaan diri warga binaan wanita. Intervensi yang dapat dilakukan adalah meningkatkan spiritualitas responden. Gangguan spiritualitas akan menyebabkan gangguan berat secara psikologis (Bele, Bodhare, Mudgalkar, Saraf, \& Valsangkar, 2012).

Oleh karena itu perawat membantu meningkatkan spiritualitas untuk lebih mendekatkan dengan Tuhan sehingga warga binaan wanita dapat menjalani hukuman dengan ikhlas tanpa harus menyalahkan orang lain, menyelesaikan permasalahan dengan korban serta tidak ada rasa untuk membalas perbuatan orang lain agar menderita. Keikhlasan menerima keadaan yang diderita berbanding lurus dengan usaha mendekatkan diri dengan Tuhan (Mailani, Setiawan, \& Cholina, 2015).

Terdapat $8 \%$ responden yang tidak akan merenung atas kesalahan di masa lampau dapat dikatakan kurangnya refreksi diri warga binaan wanita. Refleksi didefinisikan sebagai suatu pemikiran mengenai suatu masa lalu, atau suatu introspeksi (Chaplin, 2012). Perawat dapat mengajarkan warga binaan untuk merefleksikan diri misalnya mengajarkan refleksi Gibbs, langkah-langkah dalam refleksi Gibbs: mendeskripsikan peristiwa, memikirkan peristiwa, eksplorasi setiap bagian kecil dari peristiwa yang terjadi, penilaian mengenai peristiwa yang terjadi, hal baru apa yang didapatkan dari peristiwa yang terjadi, dan perencanaan tindakan apabila terjadi pengulangan peristiwa (Anantasari, 2012).

Sebanyak $20 \%$ responden memiliki rencana untuk mencari tempat tinggal baru. Responden yang berencana untuk mencari tempat tinggal baru maupun kembali di 
rumah yang dulu, membutuhkan adaptasi dengan lingkungan dengan membawa cap mantan warga binaan. Oleh karena itu peran perawat sebagai educator diperlukan dalam belajar beradaptasi dengan lingkungan masyarakat (Setiawan, Kosasih, \& Komariah, 2015).

Hasil penelitian menunjukkan bahwa 4\% responden menyatakan tidak ingin mencari pekerjaan baru yang halal, dan $52 \%$ responden memiliki rencana setelah bebas adalah tetap melanjutkan pekerjaan. Machdi menyatakan bahwa warga binaan mempunyai dua pilihan terkait pekerjaan setelah bebas yaitu kembali pada pekerjaan lama atau pekerjaan baru. Berwirausaha dipilih karena individu tidak perlu melamar pekerjaan (Machdi, 2013).

\section{KESIMPULAN DAN SARAN}

Gambaran rencana pulang warga binaan wanita sangat beragam menjelang kebebasan. Perawat correctional disarankan lebih memperhatikan masalah psikososial warga binaan wanita. Perawat correctional tidak hanya mempersiapkan kesehatan fisik saja tetapi juga mempersiapkan kesehatan mental dalam menghadapi kebebasannya. Peran perawat sebagai educator, connector, fasilitator, collaborator, advokat, praktisis kesehatan dan konselor sangat dibutuhkan dalam pelayanan correctional.

\section{DAFTAR PUSTAKA}

Al-Jauhar, B. M., \& Imron, A. (2014). Konstruksi masyarakat terhadap mantan narapidana. Jurnal Paradigma, 2(1).

Anantasari, M. L. (2012). Model refleksi Graham Gibbs untuk mengembangkan religiustas. Jurnal Teologi, 01(02), 195-207.
Andriany, M. (2008). Pengalaman narapidana wanita dalam menghadapi masa kebebasan di Lapas Wanita Kelas IIA Semarang. Universitas Indonesia.

Asmadi. (2008). Teknik prosedural keperawatan: konsep dan aplikasi kebutuhan dasar klien. Jakarta: Salemba Medika.

Bele, S., Bodhare, T. N., Mudgalkar, N., Saraf, A., \& Valsangkar, S. (2012). Health-related quality of life and existential concerns among patients with end-stage renal disease. Indian Journal of Palliative Care, 18(2), 103-108.

Chaplin, J. P. (2012). Kamus lengkap psikologi-dictionary of psychology (terjemahan Kartono, Kartini). Jakarta: Rajawali Press.

Fontana, L., \& Beckerman, A. (2007). Recently released with HIV/AIDS: Primary care treatment needs and experiences. Journal of Health Care for the Poor and Underserved, 18(3), 699-714. doi: 10.1353/hpu.2007.0058

Hitchcock, J., Schubert, P., Thomas, S. (2003). Community health nursing: caring in action. New York: Thomson Learning Inc.

Holley, U. A. (2007). Social isolation: a practical guide for nurses assisting clients with chronic illness. Rehabilitation Nursing, 32(2), 51-56.

Kellina, T. D. (2013). Pelaksanaan kegiatan kerja bagi klien pemasyarakatan (Studi di BAPAS Kelas 1 Malang). Jurnal Hukum, Februari, 1-16.

Machdi, R. (2013). Bagaimana hidup saya 
setelah ini? Aspirasi masa depan narapidana ditinjau dari perspektif kepemudaan. Jurnal Studi Pemuda, 2(1), 63-74.

Mailani, F., Setiawan, \& Cholina, T. S. (2015). Pengalaman spiritualitas pada pasien penyakit ginjal kronik yang menjalani hemodialisis. Jurnal Keperawatan Padjadjaran, 3 (1), 1117.

Mallik-Kane, K. (2005). Returning home Illinois policy brief: employment and prisoner reentry. Washington DC.

Parker, K. F., \& Reckdenwald, A. (2008). Women and crime in context: Examining the linkages between patriarchy and female offending across space. Feminist Criminology, 3(1), 524. doi: $10.1177 / 1557085107308456$

Puspitasari, V. M. (2015). Strategi adaptasi mantan narapidana di masyarakat: Studi deskriptif tentang konsep diri dan strategi adaptasi mantan narapidana terhadap stigma yang ada di masyarakat. Jurnal Universitas Airlangga, 4(1), 1-16.

Setiawan, Y., Kosasih, A., \& Komariah, S. (2015). Pola adaptasi sosial budaya kehidupan santri Pondok Pesantren Nurul Barokah. Sosietas, 5(1).

Shofia, F. (2009). Optimisme masa depan narapidana. Universitas Muhammadiyah Surakarta.

Suharso, \& Retnoningsih, A. (2005). Kamus Besar Bahasa Indonesia (Lux). Semarang: Widya Karya.

Susanto, D. B. (2013). Pola pelaksanaan bimbingan narapidana selama pembebasan bersyarat untuk tidak melakukan tindak pidana. Jurnal Hukum, Februari.

Tyaswuri, P. (2010). Implementasi life skills pelatihan ketrampilan pertukangan kayu bagi warga binaan di Lembaga Pemasyarakatan Klas IIA Yogyakarta. Universitas Negeri Yogyakarta 